\title{
Assessment of risk factors in the development of MRSA infection at Gülhane Military Medical Faculty Education Hospital and the role of antibiotic use on the development of MRSA infection
}

\author{
E Gunal $^{1 *}$, BA Besirbellioglu', F Ersoz ${ }^{2}$, IY Avci ${ }^{1}$, CP Eyigun ${ }^{1}$ \\ From International Conference on Prevention \& Infection Control (ICPIC 2011) \\ Geneva, Switzerland. 29 June - 2 July 2011
}

\section{Introduction / objectives}

This research was carried out to determine most important risk factors in the development of MRSA by comparing infections due to methicillin resistant and susceptible strains to make suggestions to decrease MRSA ratios by pointing out the importance of preinfection antibiotic usage in the development of MRSA infection and its place among the other risk factors.

\section{Methods}

This research was planned as a retrospective case control study and possible risk factors among inpatients owing to $S$. aureus infection at our hospital between 2003-2008 years, were compared as MRSA and MSSA groups.

\section{Results}

Hospitalization period, previous hospitalization existence and number, lining in intensive care unit, MRSA existence in the same unit, polymicrobial infection, acute trauma, surgery, open lesion, any intravenous, urethral catheter, mechanical ventilation, invasive device number, previous antibiotic usage, number and period of used antibiotic were found more significant in MRSA patients $(\mathrm{p}<0,05)$.Respectively, flouroquinolone usage $(\mathrm{OR}, 2,56$; \%95 CI: $1,052-6,231 ; \mathrm{p}<0,05)$, the time period of previous antibiotic use (OR, 2,343; \%95 CI: 1,697-3,236; $\mathrm{p}<0,05$ ), hospitalization times (OR, 1,396; \%95 CI: 1,235-1,578; $<<0,05)$, previous hospitalization period (OR, 0,992; \%95 CI: 0,986-0,999; p<0,05), MRSA existence in the same milieu (OR, 0,283; \%95 CI: 0,13$0,618 ; \mathrm{p}<0,05)$ were determined as independent risk factors in the development of infections due to MRSA.

\section{Conclusion}

Controlling these risk factors and either avoiding uncontrolled prescription or decreasing the use of selected antibiotic subcategories like flouroquinolones and cephalosporins seem to reduce infection due to MRSA.

\section{Disclosure of interest}

None declared.

\section{Author details}

${ }^{1}$ Infectious Disease and Clinical Microbiology, Gulhane Military Medical Academy, Turkey. ${ }^{2}$ Defense Science Institue, Turkish Military Academy, Ankara, Turkey.

Published: 29 June 2011

\section{doi:10.1186/1753-6561-5-S6-P14}

Cite this article as: Gunal et al:: Assessment of risk factors in the development of MRSA infection at Gülhane Military Medical Faculty Education Hospital and the role of antibiotic use on the development of MRSA infection. BMC Proceedings 2011 5(Suppl 6):P14.

${ }^{1}$ Infectious Disease and Clinical Microbiology, Gulhane Military Medical

Academy, Turkey

Full list of author information is available at the end of the article

(c) 2011 Gunal et al; licensee BioMed Central Ltd. This is an open access article distributed under the terms of the Creative Commons Attribution License (http://creativecommons.org/licenses/by/2.0), which permits unrestricted use, distribution, and reproduction in any medium, provided the original work is properly cited. 